\title{
Enhanced Glutathione Metabolism Is Correlated with Sulfur-Induced Resistance in Tobacco mosaic virus-Infected Genetically Susceptible Nicotiana tabacum Plants
}

\author{
Kerstin Höller, ${ }^{1}$ Lóránt Király, ${ }^{2}$ András Künstler, ${ }^{2}$ Maria Müller, ${ }^{1}$ Gábor Gullner, ${ }^{2}$ Maria Fattinger, ${ }^{1}$ and \\ Bernd Zechmann ${ }^{1}$ \\ ${ }^{1}$ University of Graz, Institute of Plant Sciences, Schubertstrasse 51, 8010 Graz, Austria; ${ }^{2}$ Plant Protection Institute, \\ Hungarian Academy of Sciences, P.O. Box 102, 1525 Budapest, Hungary
}

Submitted 21 May 2010. Accepted 21 July 2010.

Sulfur-induced resistance, also known as sulfur-enhanced defense (SIR/SED) was investigated in Nicotiana tabacum cv. Samsun nn during compatible interaction with Tobacco mosaic virus (TMV) in correlation with glutathione metabolism. To evaluate the influence of sulfur nutritional status on virus infection, tobacco plants were treated with nutrient solutions containing either sufficient sulfate $(+S)$ or no sulfate (-S). Sufficient sulfate supply resulted in a suppressed and delayed symptom development and diminished virus accumulation over a period of 14 days after inoculation as compared with $-S$ conditions. Expression of the defense marker gene $P R$ - $1 a$ was markedly upregulated in sulfate-treated plants during the first day after TMV inoculation. The occurrence of SIR/SED correlated with a higher level of activity of sulfate assimilation, cysteine, and glutathione metabolism in plants treated with sulfate. Additionally, two key genes involved in cysteine and glutathione biosynthesis (encoding adenosine $5^{\prime}$-phosphosulfate reductase and $\gamma$-glutamylcysteine synthetase, respectively) were upregulated within the first day after TMV inoculation under $+\mathrm{S}$ conditions. Sulfate withdrawal from the soil was accelerated at the beginning of the infection, whereas it declined in the long term, leading to an accumulation of sulfur in the soil of plants grown with sulfate. This observation could be correlated with a decrease in sulfur contents in TMV-infected leaves in the long term. In summary, this is the first study that demonstrates a link between the activation of cysteine and glutathione metabolism and the induction of SIR/SED during a compatible plant-virus interaction in tobacco plants, indicating a general mechanism behind SIR/SED.

Sulfur is an essential macroelement for plants and fulfills many different functions in plant growth, development, and metabolism. Plants obtain sulfur mainly from the soil as inorganic sulfate but are also able to obtain it through the atmos-

Kerstin Höller and Lóránt Király contributed equally to this work and are considered co-first authors.

Corresponding author: Bernd Zechmann; Telephone: $+43 / 316 / 380 / 5635$; Fax: +43/316/380/9880; E-mail address: bernd.zechmann@uni-graz.at

* The $e$-Xtra logo stands for "electronic extra" and indicates that eight supplementary figures and two supplementary tables are published online. phere as sulfur dioxide or hydrogen sulfide (Dahl et al. 2008; Kopriva 2006; Leustek 2002; Leustek et al. 2000). Sulfate is then transported throughout the plant and single cells by sulfate transporters. In plastids, sulfate is activated by adenylation to adenosine $5^{\prime}$-phosphosulfate, which is reduced to sulfite by adenosine 5'-phosphosulfate reductase (APR, EC. 1.8.99.2), which is a key enzyme in sulfate assimilation (Kopriva et al. 2009). Sulfite is further reduced to sulfide by sulfide reductase and is then used in plastids, mitochondria, and the cytosol to synthesize cysteine, the final product of sulfate assimilation (Hell and Wirtz 2008; Kopriva 2006; Leustek 2002; Rausch et al. 2007). In pumpkin, cysteine can be found in all cell compartments except the apoplast (Zechmann et al. 2006a). Cysteine is directly incorporated into proteins and peptides or serves as a donor of reduced sulfur for synthesis of methionine, iron-sulfur centers, and various coenzymes and secondary metabolites (Kopriva 2006; Kopriva et al. 2007). One of the most important cysteine-containing peptides is glutathione $(\gamma-$ L-glutamyl-L-cysteinyl-glycine). Glutathione has many important functions in plants, including protection against oxidative stress, heavy metals, herbicides, and xenobiotics. Glutathione is a key regulator of redox signaling and buffering and plays key roles in plant defense through the activation of defense genes (Foyer and Noctor 2009). It is also involved in the regulation of uptake, assimilation, transport, and storage of reduced sulfur (Foyer and Rennenberg 2000; Kopriva 2006; Kopriva and Rennenberg 2004; Rausch et al. 2007). Thus, glutathione metabolism can be directly linked to sulfur metabolism, which demonstrates the importance of sulfur for plant defense.

Glutathione biosynthesis in plants takes place in two ATPdependent steps. The first step of glutathione synthesis is the formation of $\gamma$-glutamyl cysteine catalyzed by $\gamma$-glutamyl cysteine synthetase (GSH1, EC 6.3.2.2). In a second step, catalyzed by glutathione synthetase (GSH2, EC 6.3.2.3), glycine is added to $\gamma$-glutamyl cysteine to form the final product glutathione (Kopriva 2006; Noctor and Foyer 1998; Noctor et al.2002; Sugiyama et al. 2004; Wachter et al. 2005; Zechmann et al. 2008a). Glutathione synthesis seems to be limited by the availability of cysteine, as glutathione contents could be increased by the supplementation or artificial elevation of cysteine (Gullner et al. 1999; Harms et al. 2000; Zechmann et al. 2007, 2008a). Additionally, a higher sulfate supply correlates with increased levels of cysteine and, subsequently, glutathione (Blake-Kalff et al. 2000; Bloem et al. 2004, 2007a; De Kok 1981; Schnug et al. 1995), and sulfur deprivation (especially in 
young leaves) strongly decreases cysteine and glutathione contents in plants (Blake-Kalff et al. 1998, 2000; Nikiforova et al. 2006; Parma et al. 2007). Expression of the GSHI gene is known to be induced by jasmonic acid (Xiang and Oliver 1998) as well as by fungal and oomycete infections (Beyer et al. 2001; Nimbalkar et al. 2006), but apparently, no report has yet been published about the effect of virus infections.

High amounts of sulfur are able to suppress disease severity in plants during fungal infection (Bloem et al. 2005; Dubuis et al. 2005; Haneklaus et al. 2009; Klikocka et al. 2005; Schnug and Haneklaus 2005; Schnug et al. 1995; Zhao et al. 2008). This process has been named sulfur-induced resistance (SIR) (Bloem et al. 2007a; Schnug et al. 1995) or sulfur-enhanced defense (SED) (Hell et al. 2005). Even though SIR/SED is commonly observed in oilseed rape and other plants during fungal infections, the mechanisms behind SIR/SED are not yet completely clear. It has been postulated that a sulfur-induced synthesis of glucosinolates, phytoalexins, thiols, or $\mathrm{H}_{2} \mathrm{~S}$ might be the key factors for the activation of SIR/SED (Bloem et al. 2007b; Dubuis et al. 2005; Kruse et al. 2007). Considering the importance of glutathione for plant metabolism and plant defense and the fact that glutathione contents are strongly correlated with sulfate supply (Bloem et al. 2007a; De Kok 1981; Kopriva 2006; Schnug et al. 1995), glutathione and cysteine may be the key components for the induction of SIR/SED. Evidence for this hypothesis comes from observations that ele- vated glutathione and cysteine contents could be correlated with a suppression of symptom development and virus contents in Cucurbita pepo (Zechmann et al. 2007). Additionally, it was shown that glutathione and cysteine contents were substantially more elevated in a resistant pumpkin cultivar than in the susceptible one during virus infection (Zechmann and Müller 2008). Similar results have been obtained in other studies on resistant tobacco plants, which showed a decrease of lesion size and numbers and virus contents after the artificial elevation of glutathione (Gullner et al. 1999). Therefore, it seems likely that glutathione metabolism is correlated with the development of SIR/SED.

The aims of this study were to investigate whether SIR/SED can be induced during a compatible Tobacco mosaic virus (TMV) infection in susceptible tobacco plants and to gain a deeper insight into the importance of glutathione metabolism during SIR/SED on the subcellular level.

\section{RESULTS}

\section{Symptom characterization and virus content.}

Symptom development was evaluated on a tripartite scale depending on the severity of symptoms on leaves and plant growth (Fig. 1, Table 1). None of the plants treated with sufficient sulfate $(+\mathrm{S})$ showed symptoms 7 days after TMV inoculation, whereas $30 \%$ of the plants grown without sulfate $(-S)$
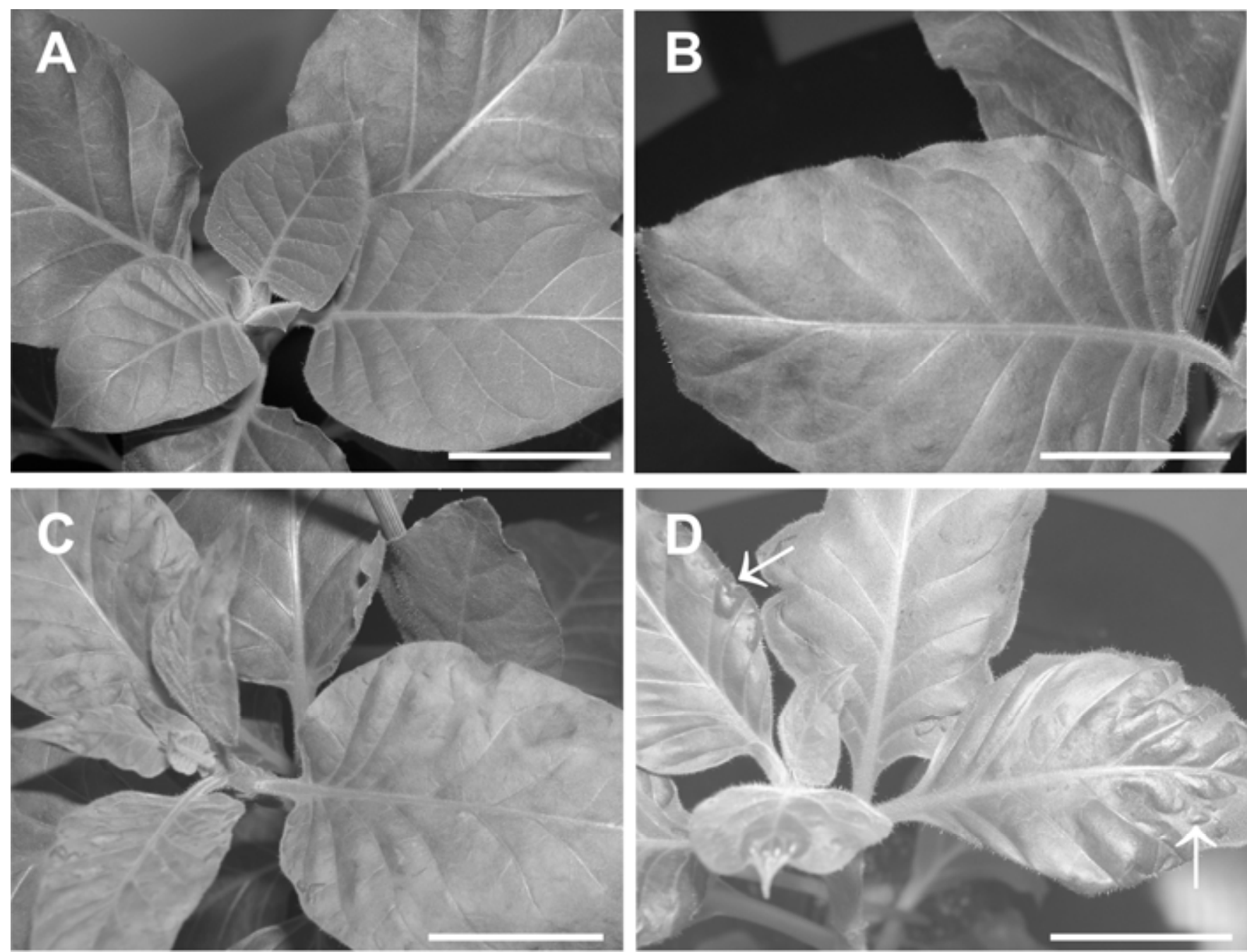

Fig. 1. Leaves of mock- and Tobacco mosaic virus (TMV)-inoculated plants demonstrating symptom appearance corresponding to a tripartite scale. Bars $=5$ $\mathrm{cm}$. A, Leaf from mock-inoculated plant without symptom, and B, TMV-infected plants with first signs of yellowing (*), C, advanced yellowing and first signs of mosaic pattern (**), and $\mathbf{D}$, green blisters (shown by arrows) and leaf deformations (***). 
showed first signs of symptoms. Two and three weeks after TMV inoculation, symptoms could be observed on all plants. Nevertheless, symptom severity was not as strong on $+\mathrm{S}$ plants two weeks after inoculation, when only $12 \%$ showed severe symptoms, whereas $50 \%$ of the $-\mathrm{S}$ plants showed severe symptoms. No differences could be observed three weeks after TMV inoculation, when $100 \%$ of the plants showed severe symptoms (Table 1).

Quantitative analysis of viral particles in the sap of leaves systemically infected with TMV revealed that, one and two weeks after TMV inoculation, 86 and $21 \%$ fewer virus particles, respectively, could be found in $+\mathrm{S}$ plants as compared with $-\mathrm{S}$ plants (Fig. 2A). No differences could be observed three weeks after virus inoculation. To investigate whether sulfate treatment also affects TMV on the level of viral RNA, we have assessed the accumulation of RNA encoding the TMV-coat protein (CP) (i.e., TMV-CP gene expression) in inoculated and systemically infected leaves (Fig. 2B, Supplementary Fig. S1). In TMVinoculated leaves 1 day after inoculation, there were no significant differences in TMV-CP RNA levels between $+\mathrm{S}$ and $-\mathrm{S}$ plants. At 2 and 4 days after inoculation, TMV-CP RNA levels were significantly lower in TMV-inoculated leaves of $+\mathrm{S}$ plants than in $-S$ plants. In systemically infected leaves at one week after TMV inoculation, TMV-CP RNA levels were slightly lower in $+S$ plants relative to $-S$ plants. Two weeks after TMV inoculation, TMV-CP RNA levels were significantly lower in plants grown with sulfate in comparison with plants grown without. However, three weeks after virus inoculation, the trend reversed as TMV-CP RNA levels became significantly higher in $+\mathrm{S}$ plants as compared with $-\mathrm{S}$ plants.

\section{Glutathione contents.}

Subcellular glutathione contents were found to be similar to what was previously observed in Cucurbita pepo and Arabidopsis thaliana plants (Müller et al. 2004; Zechmann et al. 2006a, 2008b). Highest levels of glutathione were always detected in mitochondria and lowest in chloroplasts. Intermediate labeling was detected in nuclei, the cytosol, and peroxisomes. No glutathione was detected in cell walls and intercellular spaces (Supplementary Figs. S2 and S3). Surprisingly, glutathione was also detected in vacuoles of plants treated with sulfate but was absent in vacuoles of plants grown without sulfate (Supplementary Table S1).

In mock-inoculated $-\mathrm{S}$ plants, glutathione labeling was strongly decreased over the three-week period when compared with mock-inoculated $+S$ plants. A strong decrease could also be observed in the other cell compartments. At the time of inoculation, glutathione contents were decreased between 16 (chloroplasts) and $44 \%$ (peroxisomes) (Fig. 3) in -S plants as compared with $+S$ plants. Seven, 14 , and 21 days after inoculation, plants grown on sulfate-depleted media showed a similar trend, with a decrease in glutathione contents of up to 50 (peroxisomes), 41 (nuclei), and 60\% (mitochondria), respectively (Fig. 3) . In these plants, glutathione contents remained highest in mitochondria and lowest in plastids and peroxisomes. Intermediate labeling was found in nuclei and the cytosol.
Inoculation with TMV significantly decreased glutathione contents over a period of 21 days after inoculation in most cell compartments of both $-\mathrm{S}$ and $+\mathrm{S}$ plants, when compared with mock-inoculated plants (Supplementary Fig. S4). At 7 days postinfection (dpi), $-\mathrm{S}$ plants showed a decrease between 42

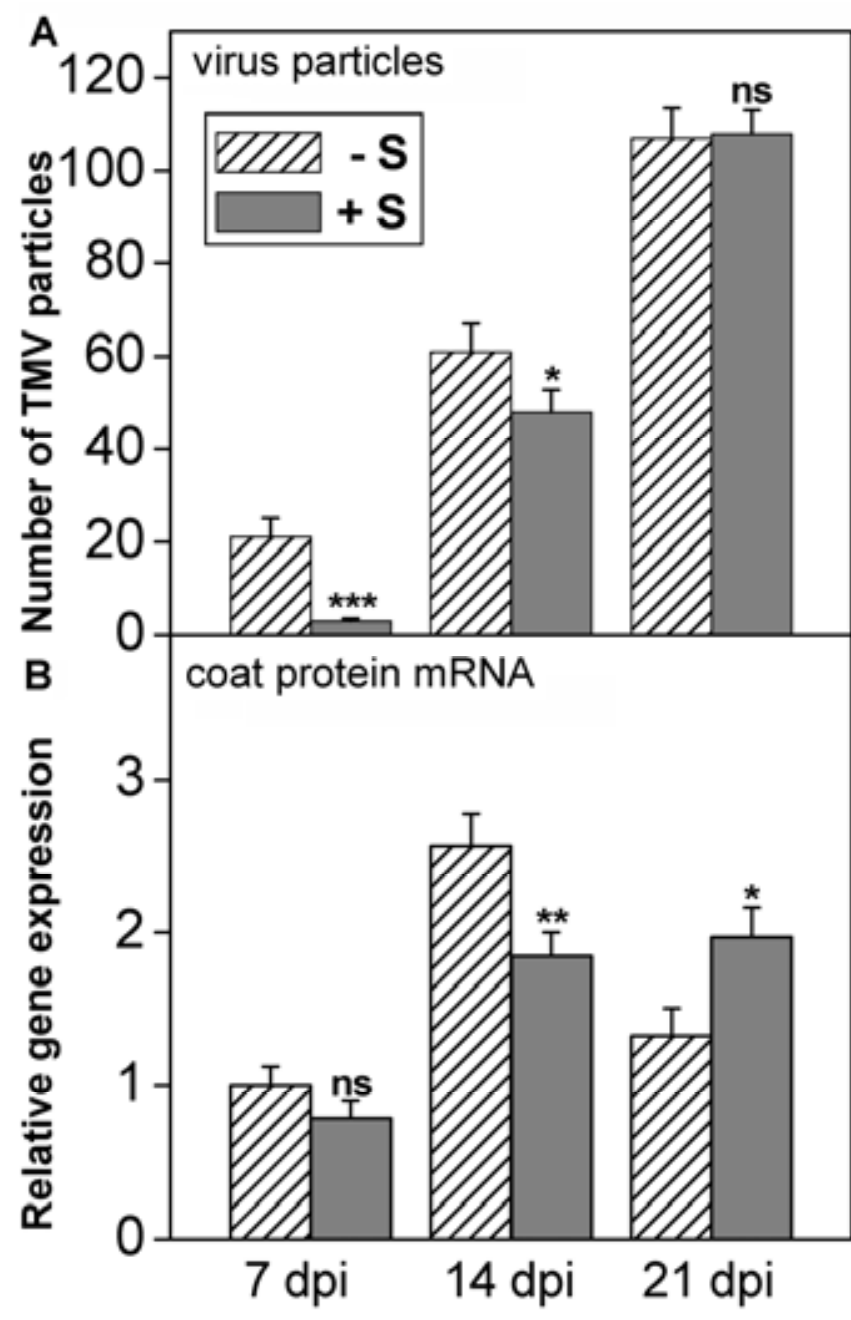

Fig. 2. Tobacco mosaic virus (TMV) particle and coat protein (CP) mRNA levels detected in leaves of systemically infected Nicotiana tabacum cv. Samsun nn plants 7, 14, and 21 days after inoculation (dpi). A, TMV particles per $100 \mu^{2}$ detected on 20 square areas (for each replicate sample) on the grid after negative staining $(n=6)$. Significant differences were calculated by using the Mann Whitney U-test. Asterisks (* and ***) indicate significance at the 0.05 and 0.001 levels of confidence, respectively. And ns = nonsignificance. B, TMV-CP mRNA levels as determined by quantitative real-time reverse transcription-polymerase chain reaction. $-\mathrm{S}$ and $+\mathrm{S}$ indicate plants grown without sulfate or with sufficient sulfate, respectively. A relative gene expression of 1 represents TMV-CP mRNA levels in systemically infected leaves at 7 dpi $(-\mathrm{S})$. Means of three independent biological experiments \pm standard error are shown. Significant differences were calculated by using the Student's $t$-test, and * and ** indicate significance at the 0.05 and 0.01 levels of confidence, respectively. ns indicates nonsignificance.

Table 1. Symptom development on Nicotiana tabacum cv. Samsun nn leaves ${ }^{\mathrm{a}}$

\begin{tabular}{|c|c|c|c|c|c|c|}
\hline \multirow[b]{2}{*}{ Symptom severity } & \multicolumn{3}{|c|}{ No sulfate (-S) } & \multicolumn{3}{|c|}{ Sufficient sulfate $(+\mathbf{S})$} \\
\hline & 7 dpi & 14 dpi & 21 dpi & 7 dpi & 14 dpi & $21 \mathrm{dpi}$ \\
\hline No symptoms $(0)$ & $70 \%$ & $0 \%$ & $0 \%$ & $100 \%$ & $0 \%$ & $0 \%$ \\
\hline First signs of yellowing on the leaves $(*)$ & $30 \%$ & $8 \%$ & $0 \%$ & $0 \%$ & $16 \%$ & $0 \%$ \\
\hline Advanced yellowing on the leaves and first signs of mosaic pattern on the leaves $(* *)$ & $0 \%$ & $42 \%$ & $0 \%$ & $0 \%$ & $72 \%$ & $0 \%$ \\
\hline Green blisters and leaf-deformation, severe mosaic pattern on the leaves $(* * *)$ & $0 \%$ & $50 \%$ & $100 \%$ & $0 \%$ & $12 \%$ & $100 \%$ \\
\hline
\end{tabular}

${ }^{a}$ Symptom development observed on Nicotiana tabacum cv. Samsun nn leaves 7, 14, and 21 days after Tobacco mosaic virus inoculation (dpi) represented as the percentage of plants showing symptoms at different severity levels ( $n=48$ for each $+\mathrm{S}$ and $-\mathrm{S}$ plants, from three different experiments). 
and $66 \%$ in all cell compartments, whereas $+S$ plants showed a significant decrease only in mitochondria $(-33 \%)$, chloroplasts $(-29 \%)$, and vacuoles $(-52 \%)$, when compared with mockinoculated plants. At this timepoint, TMV-inoculated $+S$ plants showed substantially higher glutathione contents in all cell compartments $(+125 \%$ in mitochondria, +246 in chloroplasts, +203 in nuclei, +265 in peroxisomes, +195 in the cytosol; glutathione was measurable also in vacuoles in contrast to the lack of glutathione labeling in vacuoles of -S plants), as compared with TMV-inoculated $-\mathrm{S}$ plants (Fig. 4). At 14 days after TMV inoculation, both $+\mathrm{S}$ and $-\mathrm{S}$ plants showed a significant decrease in glutathione contents only in chloroplasts (55 and
$30 \%)$ and vacuoles (51\%), as compared with mock-inoculated plants. At this time, TMV-inoculated $+\mathrm{S}$ plants contained increased glutathione contents in peroxisomes $(88 \%)$ and mitochondria (36\%), whereas all other cell compartments contained glutathione contents similar to TMV-inoculated -S plants (Fig. 4). Vacuoles also showed markedly increased glutathione levels in $\mathrm{TMV}$-inoculated $+\mathrm{S}$ plants.

At 21 days after TMV inoculation, glutathione contents were significantly decreased in plants grown with and without sulfate in mitochondria ( -39 and $-42 \%$, respectively); chloroplasts $(-22$ and $-41 \%$ ), and vacuoles ( $-20 \%$ in plants grown with sulfate), as compared with mock-inoculated plants. Nevertheless, TMV-
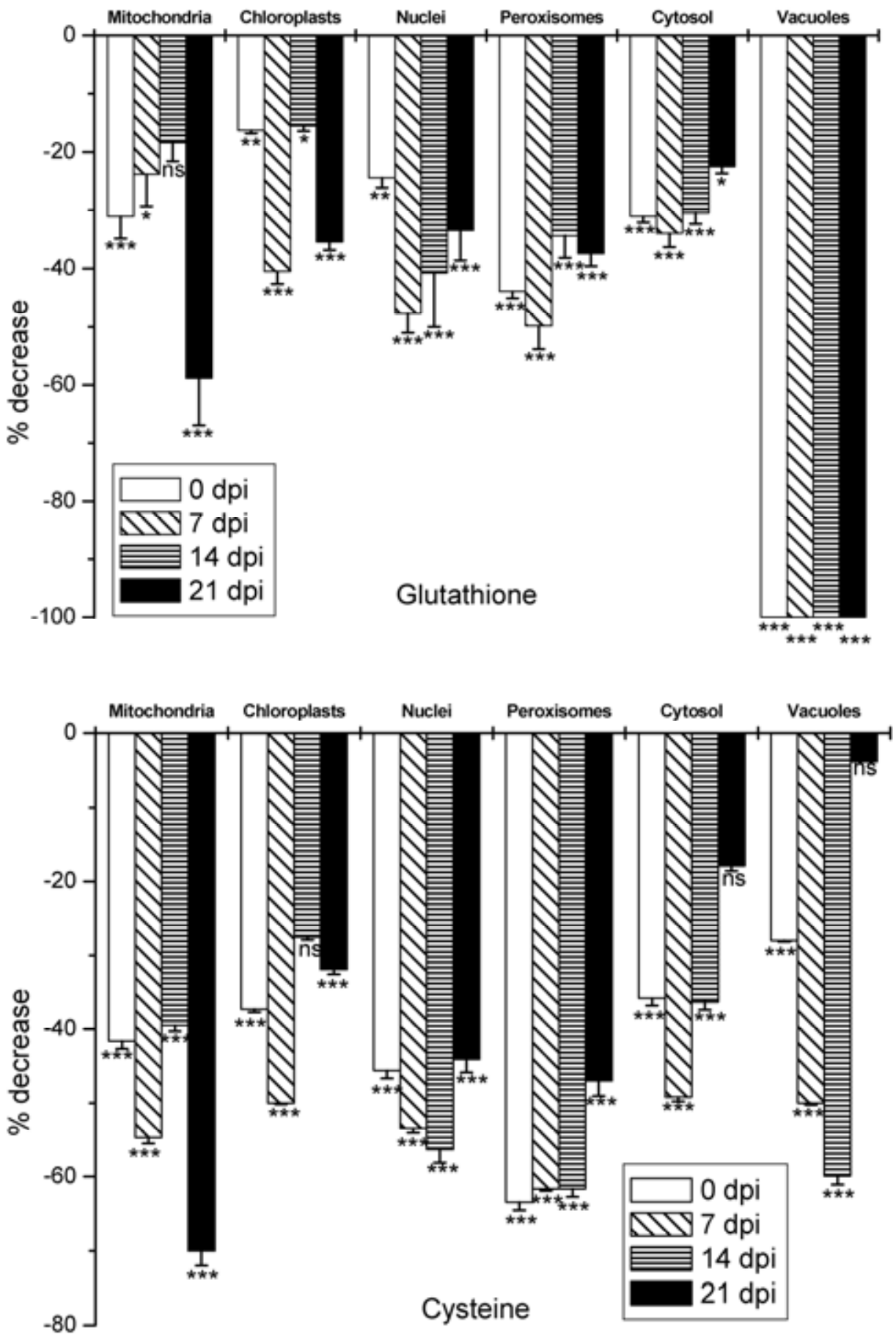

Fig. 3. Changes in glutathione and cysteine labeling density in mesophyll cells of mock-inoculated Nicotiana tabacum cv. Samsun nn grown on media without sulfate in comparison with plants grown with sulfate. Measurements were performed weekly over a time period of 21 days postinoculation (dpi). Means with standard errors are shown $(n>20$ for peroxisomes, $n>60$ for other cell structures). Significant differences were calculated using the Mann Whitney U-test; ns $=$ nonsignificance, whereas *, **, and $* * *$, respectively, indicate significance at the $0.05,0.01$, and 0.001 levels of confidence. 
inoculated $+\mathrm{S}$ plants contained substantially more glutathione in mitochondria $(154 \%)$, chloroplasts $(103 \%)$, nuclei $(97 \%)$, peroxisomes $(94 \%)$, and the cytosol $(71 \%)$, as compared with TMV-inoculated $-\mathrm{S}$ plants (Fig. 4). Measurable amounts of glutathione were also found in vacuoles of TMV-infected $+\mathrm{S}$ plants, while no glutathione was detected in those of TMVinfected $-\mathrm{S}$ plants.

\section{Cysteine contents.}

In this study, cysteine contents were found to be the highest in nuclei and the cytosol, with intermediate labeling in mitochondria, plastids, peroxisomes, and vacuoles. Cysteine was not detected in intercellular spaces and cell walls (Supplementary Figs.
S5 and S6). In -S plants, cysteine contents were generally highest in the cytosol, and similar labeling intensities were found in all other cell compartments (Supplementary Table S2).

Cysteine contents were strongly decreased over a period of 21 dpi in mock-inoculated $-\mathrm{S}$ plants when compared with $+\mathrm{S}$ ones (Fig. 3). At the time of inoculation, cysteine contents were $63 \%$ lower in peroxisomes, $46 \%$ lower in nuclei, $42 \%$ lower in mitochondria, $37 \%$ lower in chloroplasts, $36 \%$ lower in the cytosol, and $28 \%$ lower in vacuoles when compared with $+\mathrm{S}$ plants. Over the period of $21 \mathrm{dpi}$, a similar trend could be observed with a decrease in cysteine levels of up to $62 \%$ in peroxisomes ( 7 and $14 \mathrm{dpi})$ and up to $70 \%$ in mitochondria $(21$ dpi).
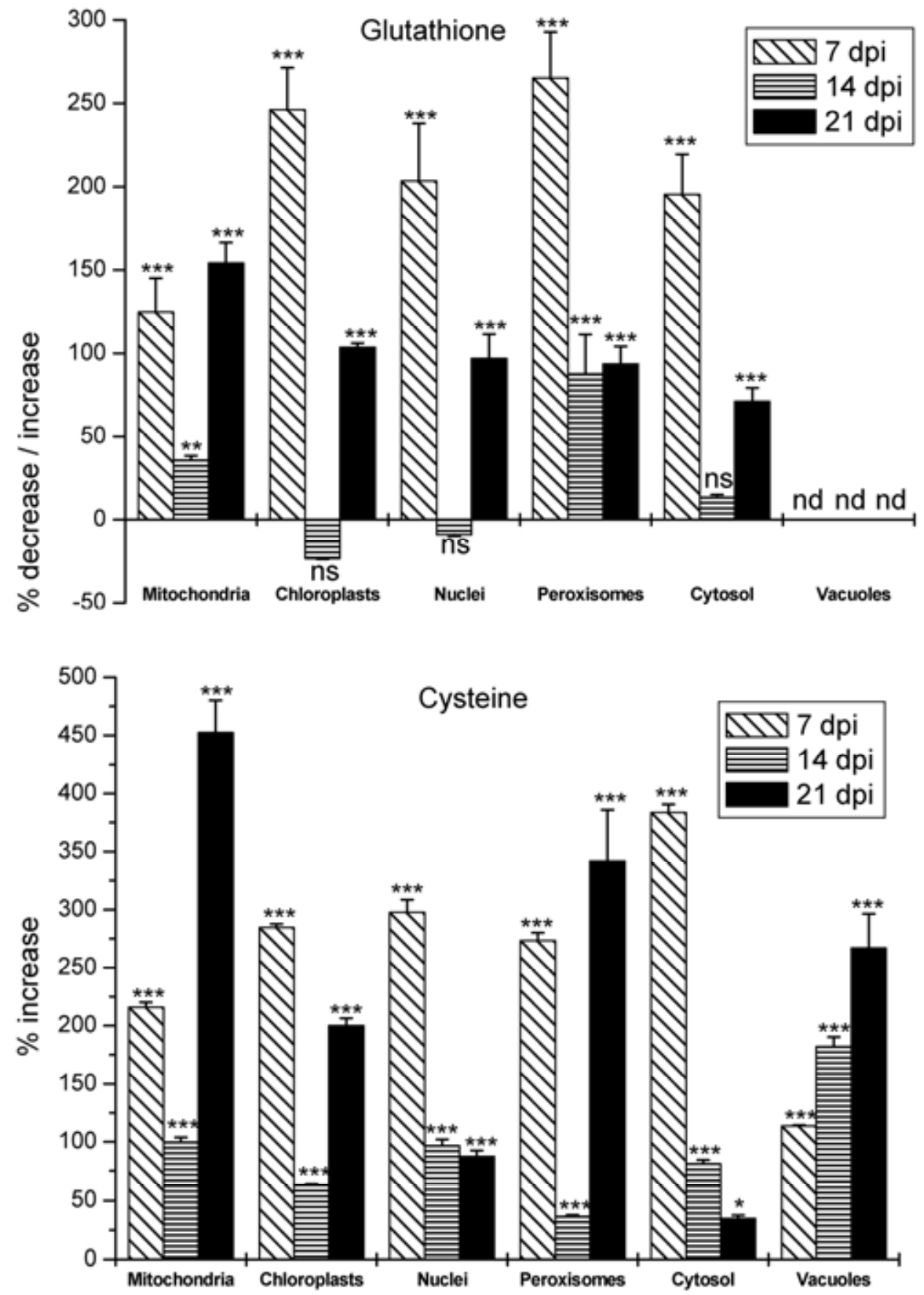

Fig. 4. Changes in glutathione and cysteine labeling density in mesophyll cells of Tobacco mosaic virus (TMV)-inoculated Nicotiana tabacum cv. Samsun nn grown with sulfate as compared with TMV-inoculated plants grown without sulfate. Measurements were performed 7, 14, and 21 days postinoculation (dpi). Means with standard errors are shown $(n>20$ for peroxisomes, $n>60$ for other cell structures). Significant differences were calculated using the Mann Whitney U-test; ns $=$ nonsignificance, whereas *, **, and $* * *$, respectively, indicate significance at the $0.05,0.01$, and 0.001 levels of confidence. Nd $=$ not determined. 
Inoculation with TMV significantly decreased cysteine contents seven days after inoculation in both $-\mathrm{S}$ and $+\mathrm{S}$ plants when compared with mock-inoculated ones (Supplementary Fig. S7a). Cysteine contents in $+S$ plants were decreased by $59 \%$ in peroxisomes, $51 \%$ in vacuoles, $42 \%$ in mitochondria, $35 \%$ in nuclei, and $27 \%$ in chloroplasts and remained unchanged in the cytosol, when compared with mock-inoculated plants. Similar results were found for $-\mathrm{S}$ plants, in which cysteine contents were significantly lower in peroxisomes $(72 \%)$, nuclei (65), chloroplasts (62), mitochondria (60), the cytosol (54), and vacuoles (53) when compared with mock-inoculated plants. At this timepoint (7 days after inoculations), cysteine contents were significantly higher in the cytosol (384\%), nuclei (298), chloroplasts (285), peroxisomes (274), mitochondria (216), and vacuoles (114) of TMV-inoculated + S plants as compared with TMV-inoculated -S plants (Fig. 4).

At 14 days after TMV inoculation, cysteine contents were increased in most cell compartments of TMV-inoculated plants as compared with the mock-inoculated plants. In TMV-inoculated + S plants, cysteine was significantly increased by $94 \%$ in mitochondria, $40 \%$ in vacuoles, $37 \%$ in nuclei, and $29 \%$ in chloroplast as compared with mock-inoculated plants. No significant differences were found in peroxisomes or the cytosol. In TMV-inoculated -S plants, cysteine contents were found to be significantly higher in peroxisomes $(101 \%)$, mitochondria (60), and nuclei (59), when compared with mock-inoculated plants. No significant changes were found in chloroplast, the cytosol, and vacuoles. At this timepoint (14 days after inoculation), cysteine contents were much higher in TMV-inoculated $+\mathrm{S}$ plants (between 37 and $182 \%$ in peroxisomes and vacuoles, respectively) than in TMV-inoculated $-\mathrm{S}$ plants (Fig. 4).

At 21 days after TMV inoculation, cysteine contents remained significantly unchanged in most cell compartments of $+\mathrm{S}$ plants compared with mock-inoculated plants. Only vacuoles showed a significant increase of $57 \%$. In TMV-inoculated $-\mathrm{S}$ plants, a strong decrease in cysteine contents could be observed in vacuoles $(-55 \%)$, chloroplasts and peroxisomes $(-53)$, and mitochondria (-26) as compared with mock-inoculated plants. At 21 days after inoculation, TMV-inoculated plants grown with sulfate contained significantly higher levels of cysteine in mitochondria (452\%), peroxisomes (342), vacuoles (267), chloroplasts (200), nuclei (88), and the cytosol (35) as compared with TMV-inoculated plants grown without sulfate (Fig. 4).

\section{Expression of the defense marker gene $P R-1 a$ and genes encoding key enzymes of cysteine and glutathione biosynthesis.}

Within the first $24 \mathrm{~h}$ after TMV inoculation, the expression of the $P R-1 a, A P R$, and GSHI genes was markedly upregu- lated, whereas that of GSH2 was not significantly affected (Figs. 5 and 6). However, a sufficient sulfate supply resulted in a further enhancement of $P R-1 a, A P R$, and $G S H 1$ expression but not expression of $G S H 2$ in TMV-inoculated leaves.

\section{Sulfur contents in leaves.}

Plants grown with sulfate contained significantly higher levels of sulfur in leaves over a period of 21 days (between 19 and $32 \%$ ) when compared with plants grown without sulfate. Over 21 days, sulfur contents in leaves varied between 3.4 and $3.7 \mathrm{mg}$ of sulfur per gram of dry weight in leaves of $+\mathrm{S}$ plants and between 2.7 and $2.9 \mathrm{mg}$ of sulfur per gram of dry weight in leaves of $-\mathrm{S}$ plants (Supplementary Fig. S8). TMV inoculation did not cause significant changes in sulfur content in leaves 7 and 14 dpi compared with mock-inoculated plants. At $21 \mathrm{dpi}$, a decrease in sulfur contents of 31 and $38 \%$ could be observed in $+\mathrm{S}$ and $-\mathrm{S}$ plants, respectively, when compared with mock-inoculated plants (Fig. 7). Interestingly, at 7, 14, and $21 \mathrm{dpi}$, sulfur contents of TMV-inoculated leaves of $+\mathrm{S}$ plants were 38,52 , and $33 \%$ higher, respectively, than in TMV-inoculated $-\mathrm{S}$ plants (data not shown).

\section{Sulfur contents in soil.}

Sulfur contents in the vermiculite-sand mixture were below the level of detection. At the time of inoculation, sulfur concentrations in the soil were found to be 365 and $112 \mathrm{mg} / \mathrm{kg}$ in soil watered with nutrient solution with and without sulfate, respectively. Whereas sulfur contents increased in the soil watered with nutrient solution with sulfate (up to $582 \mathrm{mg} / \mathrm{kg}$ ), it remained at similar levels in soil watered with nutrient solution without sulfate. TMV inoculation had major effects on sulfur contents. Sulfur contents in soil watered with sulfate were significantly lower 7 and 14 days after inoculation (322 and 476 $\mathrm{mg} / \mathrm{kg}$ ) and significantly higher $(681 \mathrm{mg} / \mathrm{kg}) 21$ days after inoculation when the soil contained plants inoculated with TMV in comparison with mock-inoculated plants. TMV inoculation induced a significant drop in sulfur contents in soil watered without sulfate to levels below detection over the period of 21 days (Fig. 8).

\section{DISCUSSION}

In order to study the importance of sulfur metabolism in the defense against viral pathogens, sulfur contents and subcellular glutathione metabolism were investigated in leaves of tobacco during a compatible TMV infection and were correlated with sulfur contents in the soil. This study revealed a tight correlation of sufficient sulfate supply with a decrease in symptom development and virus contents during a compatible TMV

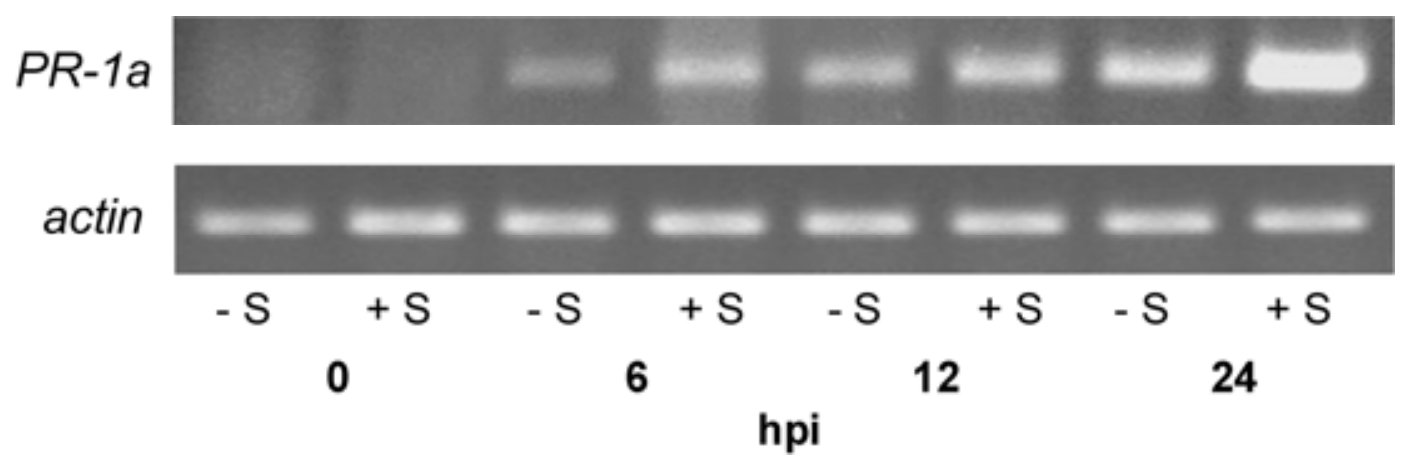

Fig. 5. Expression of the pathogenesis-related protein 1a (PR-1a) gene in leaves of Nicotiana tabacum cv. Samsun nn in response to Tobacco mosaic virus (TMV) inoculation at 6,12 , and $24 \mathrm{~h}$ after inoculation (hpi) as determined by reverse transcription-polymerase chain reaction. $-\mathrm{S}$ and $+\mathrm{S}$ indicate plants grown without sulfate or with sufficient sulfate, respectively. The expression of an actin gene was used as constitutive control. Representative results of three independent biological experiments are shown. 
infection. Similar effects have been observed during different fungal diseases (Dubuis et al. 2005; Klikocka et al. 2005), and this phenomenon was called SIR (Bloem et al. 2007a; Schnugg et al. 1995) or SED (Hell et al. 2005). Nevertheless, this is the first report demonstrating that a sufficient supply of sulfur is correlated with a decrease in disease severity and virus levels and a strong upregulation of defense genes during virus infection. Thus, these results show that SIR/SED is effective not only against fungal pathogens but also against plant viruses, indicating a general defense mechanism behind SIR/ SED. We found that virus inhibition during SIR/SED was detectable both on the level of TMV-CP RNA and CP accumulation. This is similar to the effect of salicylic acid pretreatments on TMV infection of genetically susceptible (nn) tobacco (Chivasa et al. 1997). However, inhibition of TMV during the SIR/SED response observed in this study was detected primarily on the level of TMV-CP accumulation, as the decline in TMV-CP RNA seemed to be less significant. A similar decrease in virus contents and symptom development was also

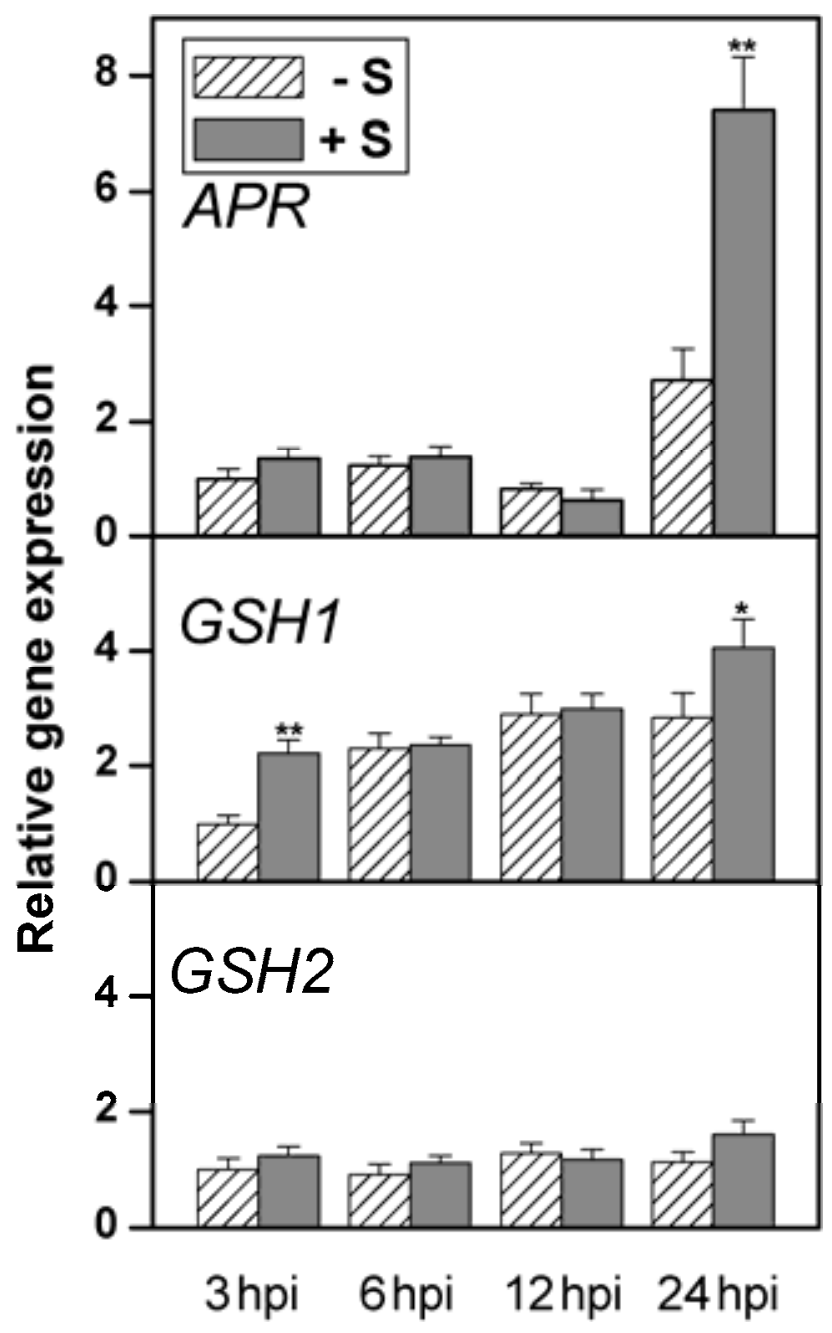

Fig. 6. Expression of adenosine $5^{\prime}$-phosphosulfate reductase $(A P R), \gamma$-glutamylcysteine synthetase $(G S H 1)$, and glutathione synthetase $(G S H 2)$ genes in leaves of Nicotiana tabacum cv. Samsun nn in response to Tobacco mosaic virus (TMV) inoculation as determined by quantitative realtime reverse transcription-polymerase chain reaction. $-\mathrm{S}$ and $+\mathrm{S}$ indicate plants grown without sulfate or with sufficient sulfate, respectively. hpi = hours postinoculation. A relative gene expression of 1 represents transcript levels in TMV-inoculated leaves at $3 \mathrm{hpi} \mathrm{(-S).} \mathrm{Means} \mathrm{of} \mathrm{three} \mathrm{independent}$ biological experiments \pm standard error are shown. Significant differences were calculated by using the Student's $t$-test. Asterisks (* and **) indicate significance at the 0.05 and 0.01 levels of confidence, respectively. reported in tobacco plants infected with TMV and pumpkin plants infected with Zucchini yellow mosaic virus after treatment with L-2-oxothiazolidine-4-carboxylic acid (OTC), a cysteine precursor and proline analog in previous studies (Gullner et al. 1999; Zechmann et al. 2007). In the latter study, it was also shown that the OTC-induced increase in cysteine contents (Zechmann et al. 2008a) led to a massive increase in glutathione contents that was correlated with a strong decrease in symptom development and virus contents over a period of five weeks. Nevertheless, such a long-term effect was not observed in the present study. Since the activation of subcellular glutathione metabolism by OTC could be directly linked to a decrease in symptom development and virus contents (Gullner et al. 1999; Zechmann et al. 2007), we tried to clarify whether differences in subcellular glutathione metabolism could be correlated with SIR/SED observed during this study.

Sulfate-treated plants contained substantially more cysteine and glutathione than plants treated without sulfate. This trend could also be observed in plants infected with TMV. These results are similar to previous studies that clearly linked a sufficient supply of sulfate with increased cysteine and glutathione biosynthesis (Blake-Kalff et al. 1998, 2000; Bloem et al. 2004, 2007a; De Kok 1981; Nikiforova et al. 2006; Parma et al. 2007; Schnug et al. 1995). Additionally, elevated cysteine and glutathione contents were found to be important for the defense against fungal and viral diseases (Bloem et al. 2007b; De Gara et al. 2003; Dubuis et al. 2005; Gullner and Kömives 2001; Gullner et al. 1999; Kruse et al. 2007; Urbanek-Krajnc et al. 2007; Zechmann et al. 2007). In this study, we were able to link the stimulation of glutathione metabolism through sulfate treatment with the upregulation of the defense marker gene $P R-1 a$ and a significant decrease in symptom development and virus contents during TMV infection. Additionally, this study revealed an upregulation of genes involved in sulfate assimilation and cysteine synthesis $(A P R)$ and glutathione synthesis $(G S H 1)$ after TMV inoculation in tobacco grown with sulfate in comparison with sulfate-depleted plants. APR encodes the key enzyme of cysteine biosynthesis (adenosine 5'-phosphosulfate reductase), while $G S H 1$ and $G S H 2$ encode two key enzymes of glutathione biosynthesis ( $\gamma$-glutamylcysteine synthetase and glutathione synthetase, respectively). Thus, these results demonstrate a clear link between a more active glutathione and cysteine metabolism and the upregulation of defense genes during SIR/SED in TMV-infected, genetically susceptible (nn) tobacco plants. Our results complement earlier findings that demonstrated a downregulation of genes involved in defense (e.g., $P R$-3) and sulfate assimilation (e.g., APR) during systemic viral infections of Arabidopsis thaliana and soybeans in the absence of SIR/SED (Babu et al. 2008; Yang et al. 2007). Thus, it can be concluded that glutathione metabolism and high glutathione and cysteine contents in general are key requirements for the development of SIR/SED during virus diseases.

TMV infection induced compartment-specific changes in glutathione and cysteine contents on the subcellular level over the timecourse of the experiment, which fit into the timedependent stress response concept described by Tausz and associates (2004). Glutathione and cysteine contents dropped severely 7 days after TMV inoculation in most cell compartments, when first symptoms occurred on the leaves, indicating an initial stress response in these leaves. At 14 days after TMV inoculation, glutathione levels were restored in some cell compartments but remained decreased in chloroplasts and vacuoles. Cysteine levels, on the other hand, were restored in all cell compartments and strongly increased in some of them (e.g., mitochondria, nuclei, peroxisomes). Thus, these data indicate that TMV-inoculated leaves went through an acclimation reac- 
tion in which large amounts of cysteine were synthesized or mobilized, most probably to assuage the increased need for glutathione production for antioxidative defense. Nevertheless, 21 days after inoculation, when all plants showed severe symp- toms of TMV-induced disease, glutathione contents remained similar to levels reached 14 days after TMV inoculation. The most severe drop in glutathione contents in TMV-infected leaves at this stage was observed in mitochondria, which is

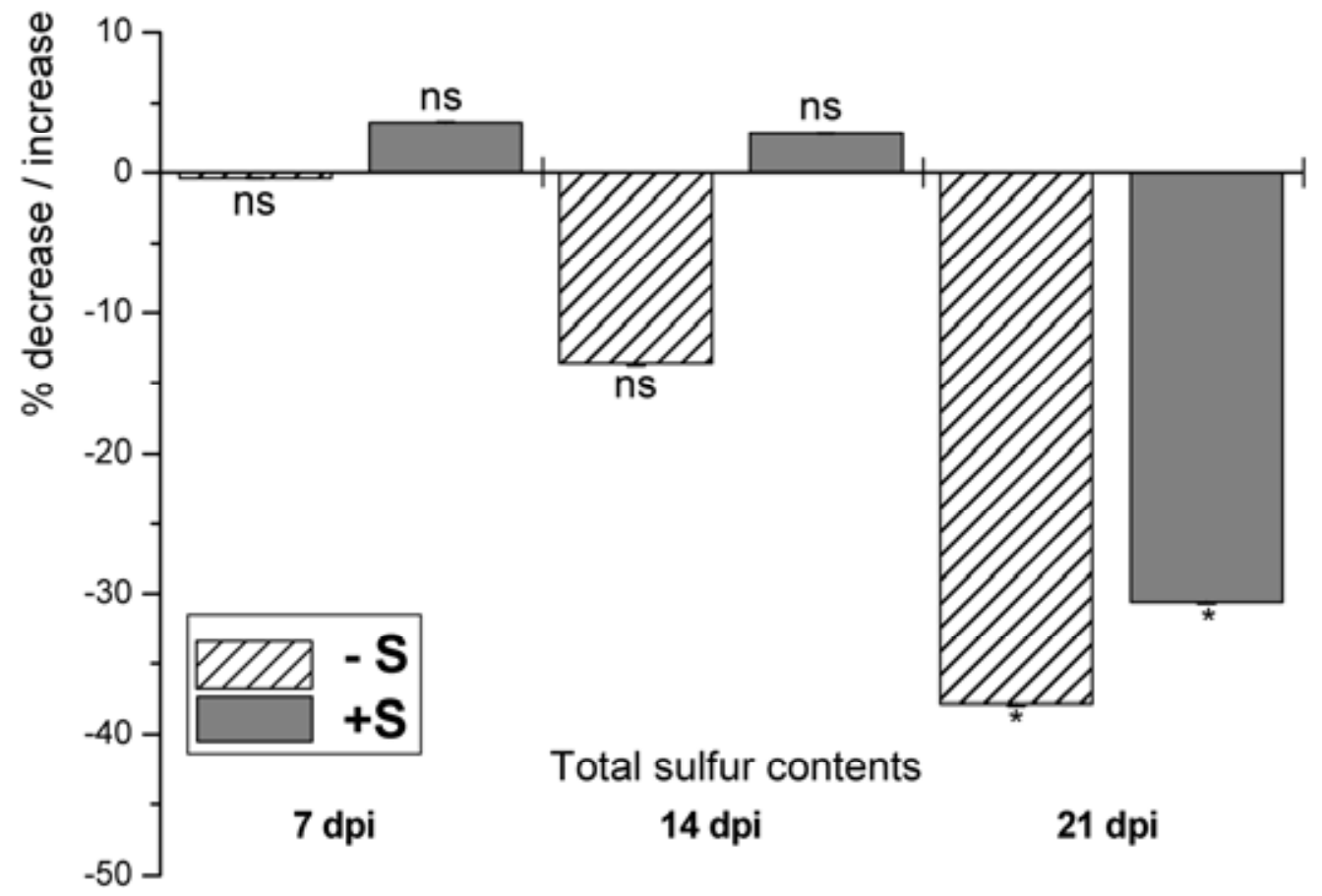

Fig. 7. Changes in total sulfur contents in leaves of Tobacco mosaic virus (TMV)-inoculated Nicotiana tabacum cv. Samsun nn plants grown with (gray columns) or without sulfate (diagonally striped columns) in comparison to mock-inoculated plants. Measurements were performed weekly over a time period of 21 days postinoculation (dpi), with six or more replicate samples for each measurement. Data are means with standard errors. Significant differences were calculated using the Mann Whitney U-test; ns = nonsignificance; * indicates significance at the 0.05 level of confidence.

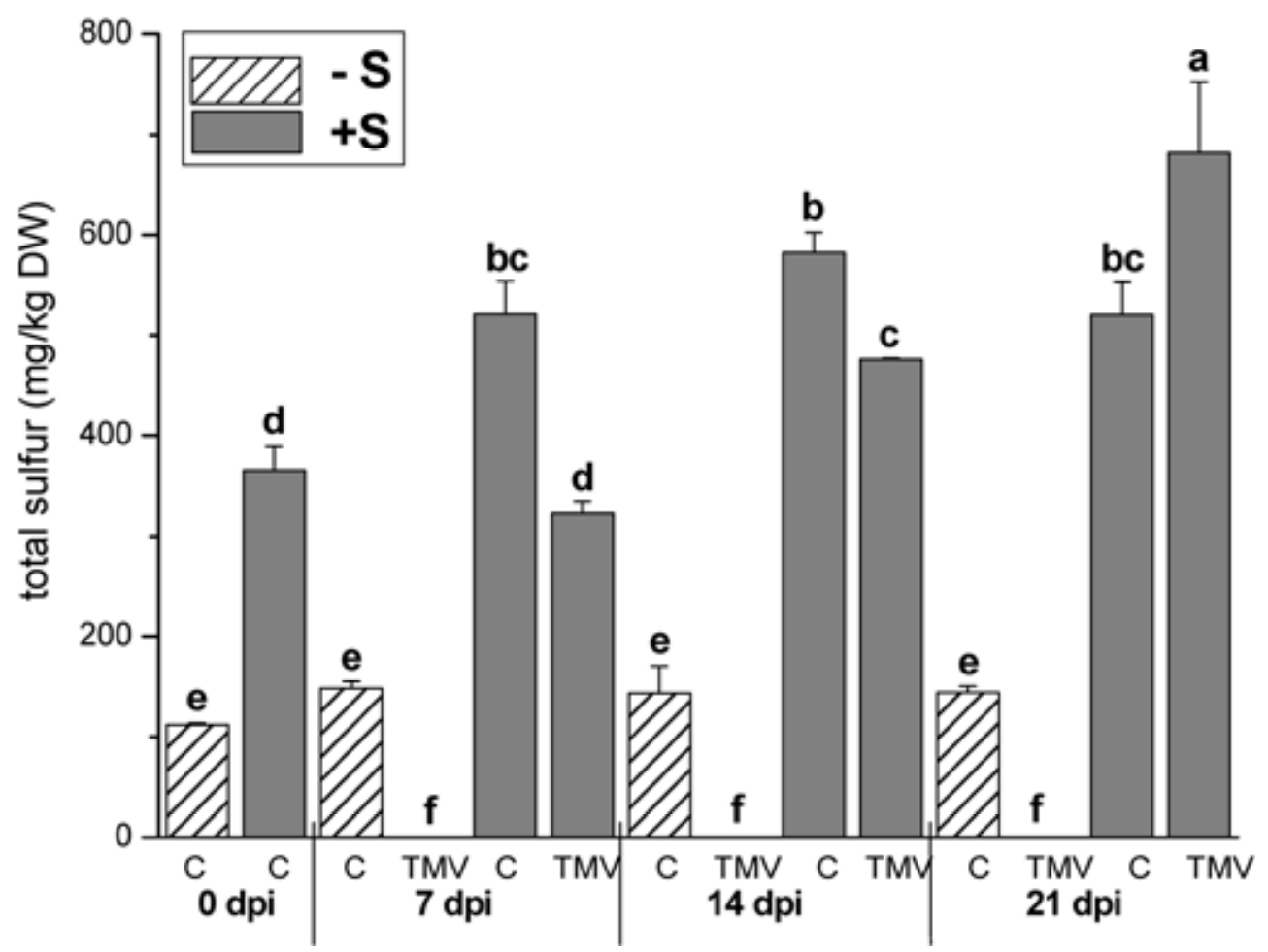

Fig. 8. Total amount of sulfur, measured in $\mathrm{mg} / \mathrm{kg}$ dry weight (DW), in the soil of Nicotiana tabacum cv. Samsun nn plants grown with (gray columns) and without (diagonally striped columns) sulfate. Measurements were performed over a period of 21 days postinoculation (dpi) in plants inoculated with Tobacco mosaic virus (TMV) and in mock-inoculated control plants (C). Plants grown without sulfate received one single dose (5 ml) of Hoagland solution with sulfate when transferred onto sand-vermiculite mixture, which did not contain measureable amounts of sulfur. Data are means with standard errors. Different lowercase letters indicate significant differences $(P<0.05)$, analyzed with the Kruskal-Wallis test, followed by post-hoc comparison according to Conover. 
especially interesting, as we found that high and stable levels of glutathione in mitochondria play important roles for plant development and cell survival (Zechmann and Müller 2008, 2010). Cysteine contents at this stage were much lower when compared with levels reached 14 days after inoculation. Thus, TMV-inoculated plants went through only a weak acclimation reaction that did not lead to a long-term increase and acclimation of the antioxidative system. Considering the time-dependent stress-response concept described by Tausz and associates (2004) and the severity of symptoms on TMV-infected plants 21 days after inoculation, it seems that these plants were going through depletion and degradation of the antioxidative system that eventually led to senescence and death of leaves.

On the subcellular level, it is also interesting that glutathione contents in chloroplasts remained decreased over the whole investigation period in TMV-inoculated plants, demonstrating that chloroplasts, in contrast to other cell compartments, were never able to acclimate to TMV-induced oxidative stress. These results indicate either that chloroplasts are especially in need of protection by glutathione during pathogen attack or that large amounts of glutathione are withdrawn from the chloroplasts in order to assuage the higher demand in other cell compartments. Considering that photosynthesis is negatively affected by virus infection leading to the accumulation of reactive oxygen species (Ma et al. 2008; Sajnani et al. 2007), the first option seems to be more likely.

Vacuoles did not show glutathione labeling in $-\mathrm{S}$ plants, but glutathione could be detected in vacuoles of plants treated with sulfate. Cysteine contents in vacuoles were also found to be much higher (about twofold) in $+S$ plants when compared with $-\mathrm{S}$ plants. Thus, these results demonstrate that vacuoles can act as a sink for glutathione and cysteine when concentrations get (too) high in the cytoplasm. It is known that vacuoles can act as a sink for elemental sulfur, which can be released into the cytosol when needed, e.g., when cysteine and glutathione contents decline (Kataoka et al. 2004; Kruse et al. 2007; Parmar et al. 2007). A similar mechanism might also apply for glutathione and cysteine, as TMV inoculation induced an initial withdrawal of cysteine and glutathione from the vacuoles over the whole period of the experiment after TMV inoculation. This correlated with an initial decrease in cysteine and glutathione contents after TMV inoculation in the cytoplasm.

It is interesting that sulfur contents in the soil were strongly affected by TMV inoculation. Soil sulfur contents significantly dropped 7 days after TMV inoculation. These results can be correlated with decreased glutathione and cysteine contents in tobacco 7 days after TMV inoculation. These results indicate an increased demand for sulfate at the beginning of infection, apparently in order to assuage the higher demand of sulfur for plant defense against TMV infection. The mechanisms behind these observations are not yet completely clear but indicate that low cysteine and glutathione contents in leaves might have stimulated the uptake of sulfate during virus infection, as both compounds are involved in the regulation of sulfate uptake and assimilation (Kopriva and Rennenberg 2004; Rennenberg et al. 1988).

A strong accumulation of sulfur in the soil could be observed in TMV-inoculated plants grown on media with sulfate $21 \mathrm{dpi}$, when all plants showed severe systemic symptoms of TMV infection. As sulfur soil contents remained decreased 7 and 14 dpi, it seems that TMV inoculation triggers only an immediate response for higher sulfate uptake, whereas in the later stages of infection, sulfur accumulation can be found in the soil, most probably due to a distorted sulfate uptake. This is in line with the results from sulfur contents in the leaves. Even though plants grown with sulfate contained generally much higher levels of sulfur, sulfur contents in the leaves remained unchanged
7 and 14 days after TMV inoculation but were strongly decreased 21 days after TMV inoculation in both types of samples as compared with mock-inoculated plants. Thus, it seems that, even though sulfate uptake is enhanced at the beginning of infection and distorted in the long term, the incorporation of sulfate from the soil into the leaves is not disturbed at the beginning of infection. In the long term, a decrease in sulfur content in the leaves and an accumulation in the soil of TMV-inoculated plants can be observed, indicating that virus infection distorted the uptake and incorporation of sulfate in the leaves.

In summary, the present study is the first to indicate a clear link between SIR/SED and the activation of glutathione metabolism during a compatible plant-virus interaction.

\section{MATERIALS AND METHODS}

\section{Plant material and virus inoculation.}

Seeds of Nicotiana tabacum cv. Samsun nn (obtained from the German Resource Center for Biological Material, DSMZ, Braunschweig, Germany) were germinated on quartz sand. Three-week-old seedlings were transferred into a mixture of quartz sand and vermiculite (1:3) and were cultivated in growth chambers under a photoperiod of $12 \mathrm{~h}$ (PAR 400 to 700 $\mathrm{nm})$, with a light intensity between 130 and $170 \mu \mathrm{mol} \mathrm{m} \mathrm{m}^{-2} \mathrm{~s}^{-1}$, day and night temperatures of 22 and $18^{\circ} \mathrm{C}$, respectively, and a relative humidity of $70 \%$.

After transferring tobacco plants on the sand-vermiculite mixtures, they were provided with nutrient solutions containing either $+\mathrm{S}$ or $-\mathrm{S}$ over the whole time of the experiment. $-\mathrm{S}$ plants received one single dose $(5 \mathrm{ml})$ of Hoagland solution with sulfate when transferred onto the sand-vermiculite mixture, which did not contain measureable amounts of sulfur. This treatment assured that $-\mathrm{S}$ plants reached the adult stage, which was not the case if plants were raised solely with nutrient solution without sulfate. $+\mathrm{S}$ plants were watered with a nu-

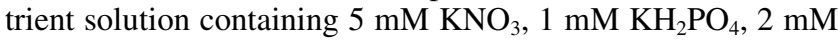
$\mathrm{Mg}\left(\mathrm{NO}_{3}\right)_{2} \times 6 \mathrm{H}_{2} \mathrm{O}, 2.5 \mathrm{mM} \mathrm{CaSO}_{4} \times 2 \mathrm{H}_{2} \mathrm{O}, 1 \mathrm{mM} \mathrm{MgSO}_{4} \times$ $7 \mathrm{H}_{2} \mathrm{O}, 70 \mu \mathrm{M}$ EDTA-FeNa, $4 \mathrm{mM} \mathrm{Ca}\left(\mathrm{NO}_{3}\right)_{2} \times 4 \mathrm{H}_{2} \mathrm{O}, 0.9 \mu \mathrm{M}$ $\mathrm{ZnCl}_{2}, 30 \mu \mathrm{M} \mathrm{H}_{3} \mathrm{BO}_{3}, 0.9 \mu \mathrm{M} \mathrm{CuCl}_{2} \times 2 \mathrm{H}_{2} \mathrm{O}, 0.5 \mu \mathrm{M} \mathrm{MoO}_{3}$, and $20 \mu \mathrm{M} \mathrm{MnCl}_{2} \times 4 \mathrm{H}_{2} \mathrm{O}$. Whereas watering with this nutrient solution continued with the group of $+S$ plants over the whole duration of the experiment, the $-\mathrm{S}$ group of plants received the same solution without sulfate-containing components $\left(2.5 \mathrm{mM} \mathrm{CaSO}_{4} \times 2 \mathrm{H}_{2} \mathrm{O}\right.$ was exchanged for $0.86 \mathrm{mM}$ $\mathrm{CaCl}_{2}$, and $1 \mathrm{mM} \mathrm{MgSO} 4 \times 7 \mathrm{H}_{2} \mathrm{O}$ was not applied) until the end of the experiment. The $\mathrm{pH}$ values of the solutions were adjusted from a $1-\mathrm{mM}$ potassium hydroxide solution to around 6.5. Four weeks after transferring the plants to the sand-vermiculite mixture, they were inoculated with Tobacco mosaic virus (TMV). Cotyledons and first true leaves were inoculated with the sap of TMV-infected tobacco plants (strain i.d. for TMV: DSMZ PV-0107; TMV-vulgare/U1; geographical origin, Germany; obtained from the German Resource Center for Biological Material). For inoculation, $1 \mathrm{~g}$ of TMV-infected leaf material (youngest fully developed leaves from TMV-infected Nicotiana tabacum cv. Samsun nn plants with strong visual symptoms) was homogenized in $1 \mathrm{ml}$ of a $1 \% \mathrm{~K}_{2} \mathrm{HPO}_{4}$ solution ( $\mathrm{pH}$ 6.8). The inoculum-containing celite (Sigma-Aldrich, St. Louis) was rubbed onto the cotyledons and first true leaves. Mock-inoculation was performed on the remaining plants, which served as controls, by rubbing a homogenate containing the sap of healthy plants, a $\mathrm{K}_{2} \mathrm{HPO}_{4}$ solution ( $\mathrm{pH}$ 6.8), and celite onto the cotyledons and first true leaves. Inoculated and mock-inoculated plants were placed randomly inside the growth chambers. Care was taken to ensure that inoculated and mock-inoculated plants did not touch each other during the experiment. 
Symptom characterization.

Symptom development was visually evaluated 1,2 , and 3 weeks after TMV inoculation, on a total of 96 plants $(48+\mathrm{S}$ and $48-S$ plants) from three different experiments. Plants were classified depending on the severity of TMV-induced symptoms using the following scale: $0=$ no symptoms; $*$ = first signs of yellowing on the leaves; $* *=$ advanced yellowing on the leaves and first signs of mosaic pattern; $* * *=$ green blisters and leaf deformation (Fig. 1, Table 1). Symptoms of the 48 TMV-infected plants derived from three different experiments were evaluated for plants cultivated on media both with and without sulfate.

\section{Electron microscopical studies.}

Negative staining and quantification of viral particles. Negative staining and quantification of viral particles was performed as described previously (Zechmann et al. 2007). Briefly, 10-mg leaf samples were homogenized in $100 \mu \mathrm{l}$ of $0.06 \mathrm{M}$ phosphate buffer, and $20 \mu \mathrm{l}$ of the homogenate was applied on top of a formvar-coated grid for $5 \mathrm{~min}$, and then, washed in buffer and stained with $2 \%$ phosphotungstic acid for 2 min. For statistical analysis, TMV particles were counted on 20 defined square areas for each replicate sample on the grid after negative staining ( $n=6$ plants for each data set), and the data was analyzed with the software program Statistica (StatSoft, Tulsa, OK, U.S.A.) by using the Mann Whitney U-test (Bortz et al. 2000). Statistical differences were determined at the $0.05,0.01$, and 0.001 levels of confidence.

Electron microscopy and immunogold labeling of glutathione and cysteine. Preparation of the sample for transmission electron microscopy and immunogold labeling of glutathione and cysteine (including negative controls) was done with ultrathin sections on nickel grids as described previously (Zechmann and Müller 2010; Zechmann et al. 2006a). Small samples of the youngest fully developed leaves were fixed in $2.5 \%$ paraformaldehyde and $0.5 \%$ glutardialdehyde in $0.06 \mathrm{M}$ phosphate buffer ( $\mathrm{pH}$ 7.2) for $90 \mathrm{~min}$. Samples were rinsed in buffer, were dehydrated in increasing concentrations of acetone $(50,70$, and $90 \%$ ), and were infiltrated with increasing concentrations of LR-White resin (30, 60, and 100\%; London Resin Company Ltd., Berkshire, U.K.). Samples were finally embedded in LRWhite resin and were polymerized at $50^{\circ} \mathrm{C}$ for $48 \mathrm{~h}$ in small plastic containers. Ultrathin sections of the samples were blocked with $2 \%$ bovine serum albumin in phosphate buffered saline (PBS, pH 7.2) and were then treated with the primary antibodies (anti-glutathione rabbit polyclonal immunoglobulin $\mathrm{G}$ [IgG] and anti-cysteine rabbit polyclonal IgG; Millipore Corp., Billerica, MA, U.S.A.) diluted 1:50 (glutathione antibody) and 1:300 (cysteine antibody) in PBS containing 1\% goat serum for $2 \mathrm{~h}$ at room temperature. After a short rinse in PBS, samples were incubated with a $10-\mathrm{nm}$ gold-conjugated secondary antibody (goat anti-rabbit IgG; British BioCell International, Cardiff, U.K.) diluted 1:50 in PBS for $90 \mathrm{~min}$ at room temperature. After a short wash in PBS and distilled water, labeled grids were observed in a Philips CM10 transmission electron microscope. At least four different samples from mock- and TMV-infected leaves were examined for statistical evaluation. A minimum of 20 (peroxisomes and vacuoles) to 60 (other cell structures) sectioned cell structures of at least 15 different cells were analyzed for gold particle density. The obtained data were statistically evaluated using Statistica and were presented as the number of gold particles per square micrometer or as changes in percentages. For statistical analyses of the total number of gold particles, the nonparametric KruskalWallis test, followed by a post-hoc comparison according to Conover, was used (Bortz et al. 2000). $P<0.05$ was regarded as significant. To determine significantly different changes in percentage, the Mann Whitney U-test was used (Bortz et al. 2000). Statistical differences were determined at the 0.05 , 0.01 , and 0.001 levels of confidence.

\section{Biochemical studies.}

Sulfur contents in soil. Sulfur contents in soil were measured according to Kirsten and Nordenmark (1987), with an automated elemental analyzer (Carlo Erba NA 1500 [Thermo Fisher Scientific, Waltham, MA, U.S.A.]). Briefly, soil samples were dried at $80^{\circ} \mathrm{C}$ for 3 days and were sieved (corn size $<2 \mathrm{~mm}$ ). Samples were ground (corn size $<63 \mu \mathrm{m}$ ) and burned in the elemental analyzer over copper oxide with oxygen injected into the carrier gas. Combustion gases were reduced with copper. Water was absorbed, and sulfur dioxide was separated from carbon dioxide and nitrogen. Sulfur contents were then determined using the software Agilent Chemstation 32 (Agilent Technology, Santa Clara, CA, U.S.A.). The obtained data were statistically evaluated using Statistica. For statistical analyses, the nonparametric Kruskal-Wallis test was used, followed by a post-hoc comparison according to Conover (Bortz et al. 2000). $P<0.05$ was regarded significant.

Sulfur contents in leaves. Total sulfur contents in leaves were determined according to Pilch and Grill (1995). Briefly, dried leaves $\left(4\right.$ days at $80^{\circ} \mathrm{C}$ ) were combusted at $900^{\circ} \mathrm{C}$ in a closed system and the gases were absorbed in $3 \%$ hydrogen peroxide. The ash was wetted with distilled water and shaken at $100^{\circ} \mathrm{C}$ in a water bath for $3 \mathrm{~h}$. Aliquots of the solutions were used to determine total sulfur contents (as sulphate) for each sample by high-performance liquid chromatography equipped with an autosampler (LDC Milton Roy CM 4000 [Milton Roy, Ivyland, PA, U.S.A.] with autosampler Spark Holland Basic Marathon [Spark Holland B. V., Emmen, The Netherlands]). Ions were separated with an anion exchange column (Hamilton PRP-X100, Hamilton Bonaduz AG, Bonaduz, Switzerland)). The ions were detected with a conductivity detector (ESA IonChem Model 5400 [ESA, Chelmsford, MA, U.S.A.]), and the signals were processed with a computer software. Significant differences were calculated with the Mann Whitney U-test by using Statistica. Statistical differences were determined at the $0.05,0.01$, and 0.001 levels of confidence (Bortz et al. 2000).

\section{Total RNA extraction and gene expression analysis.}

At least $200 \mathrm{mg}$ of fresh leaves per sample from TMV- or mock-inoculated leaves were homogenized in liquid nitrogen. For total RNA isolation, $100 \mathrm{mg}$ of homogenized plant material was used by applying a total RNA isolation minicolumn kit according to the manufacturer's instructions (Viogene, Sunnyvale, CA, U.S.A.). Total RNA preparations $(2 \mu \mathrm{g})$ were used for reverse transcription (i.e., first-strand cDNA synthesis) by applying a RevertAid $\mathrm{H}^{-}$M-MuLV RT kit (MBI Fermentas, Vilnius, Lithuania). In the case of analysis of tobacco gene expression, only the oligo (dT) primer was used for reverse transcription, while in the case of assessing TMV-CP RNA levels (i.e., TMV CP gene expression), a mixture of oligo (dT) and a 3' primer specific for the TMV-CP gene (discussed above) was used, following instructions of the manufacturer.

Semiquantitative PCR for assaying tobacco $P R-1 a$ gene expression was conducted with reagents supplied by KAPA Biosystems (Woburn, MA, U.S.A.), always using $2 \mu \mathrm{l}$ of template cDNA in a total reaction volume of $25 \mu \mathrm{l}$, according to instructions of the manufacturer. PCR reactions were carried out with a PTC 200 DNA Engine (MJ Research, Waltham, MA, U.S.A.). Expression of a tobacco actin gene (GenBank accession X69885) served as a reference (constitutive control) of gene expression. Quantitative real-time PCR (qPCR) for assaying expression of cysteine and glutathione biosynthesis 
genes (APR, GSH1, and GSH2) and the TMV-CP gene was conducted with the $2 \times$ SYBR FAST Readymix reagent (KAPA Biosystems), always using $2.5 \mu \mathrm{l}$ of a 25 -fold dilution of template cDNA in a total reaction volume of $15 \mu \mathrm{l}$, following instructions of the manufacturer. Thermocycling was conducted in a DNA Engine Opticon 2 instrument (MJ Research). Changes in transcript abundance (gene expression) were calculated using the $2^{-\triangle \Delta \mathrm{CT}}$ method (Livak and Schmittgen 2001), using expression of a tobacco actin gene (GenBank accession $\mathrm{X69885)}$ as an internal control. Gene expression in TMVinoculated samples was also normalized to that in mock-inoculated samples.

Oligonucleotide primers used in RT-PCR were the following: 5'-CGGAATCCACGAGACTACATAC-3' (5' primer [forward]) and 5'-GGGAAGCCAAGATAGAGC-3' (3' primer [reverse]) for a 230-bp tobacco actin cDNA fragment (GenBank accession X69885); 5'-GCAGATTGTAACCTCGTA-3' (5' primer) and 5'-CAATTAGTATGGACTTTCG-3' (3' primer) for a 297-bp tobacco pathogenesis-related gene 1a $(P R-1 a)$ cDNA fragment (D90196); 5'-CATGTTCCCTGACGCTGTT GA-3' (5' primer) and 5'-GGCATCTTCCCACCACCATCT-3' (3' primer) for a 430-bp tobacco $A P R$ gene cDNA fragment (AY648056); 5'-TAATGCCGAAGGGGAGATACG-3' primer) and 5'-GCCGGGAATAGGGGAAAGT-3' (3' primer) for a 434-bp tobacco GSH1 gene cDNA fragment (DQ444219); 5'-AGTGCCCTTCAATTTCCTATCAT-3' (5' primer) and 5'CTCCGCATTCAACCCCAGTA-3' (3' primer) for a 574-bp tobacco putative $G S H 2$ gene cDNA fragment (EB437755); $5^{\prime}$ CTTGTCATCAGCGTGGGC-3' (5' primer) and 5'-AAGTCA CTGTCAGGGAAC-3' ( $3^{\prime}$ primer) for a 165 -bp TMV-CP gene cDNA fragment (AJ429078). All oligonucleotide primers were designed with the aid of the Primer Premier 5 program (PREMIER Biosoft International, Palo Alto, CA, U.S.A.).

Statistical differences have been determined by using Statistica. For statistical analysis of TMV coat protein mRNA levels and the expression of $A P R, G S H 1$, and GSH2 genes, the Student's $t$-test was used. Significant differences were determined at the $0.05,0.01$, and 0.001 levels of confidence.

\section{ACKNOWLEDGMENTS}

This work was supported by the Austrian Science Fund (FWF-Project nr. 20619 to B. Zechmann), and grants from the Hungarian Scientific Research Fund (OTKA K 77641 and K77705) and by Austrian-Hungarian exchange grants (WTZ HU 10-2009 and AT-3/2008). We would like to thank E. Brauner from the University of Natural Resources and Applied Life Sciences in Vienna for soil analysis.

\section{LITERATURE CITATIONS}

Babu, M., Gagarinova, A. G., Brandle, J. E., and Wang, A. 2008. Association of the transcriptional response of soybean plants with Soybean mosaic virus systemic infection. J. Gen. Virol. 89:1069-1080.

Beyer, K., Binder, A., Boller, T., and Collinge M. 2001. Identification of potato genes induced during colonization by Phytophthora infestans. Mol. Plant Pathol. 2:125-134.

Blake-Kalff, M. M. A., Harrison, K. R., Hawkesford, M . J., Zhao, F. J., and McGrath, S. P. 1998. Distribution of sulfur within oilseed rape leaves in response to sulfur deficiency during vegetative growth. Plant Physiol. 118:1337-1344.

Blake-Kalff, M. M. A., Hawkesford, M. J., Zhao, F. J., and McGrath, S. P. 2000. Diagnosing sulfur deficiency in field-grown oilseed rape (Brassica napus L.) and wheat (Triticum aestivum L.). Plant Soil 225:95-107.

Bloem, E., Riemenschneider, A., Volker, J., Papenbrock, J., Schmidt, A., Salac, I., Haneklaus, S., and Schnug, E. 2004. Sulphur supply and infection with Pyrenopeziza brassicae influence L-cysteine desulphydrase activity in Brassica napus L. J. Exp. Bot. 55:2305-2312.

Bloem, E., Haneklaus, S., and Schnug, E. 2005. Significance of sulfur compounds in the protection of plants against pests and diseases. J. Plant Nutr. 28:763-784.

Bloem, E., Haneklaus, S., and Schnug, E. 2007a. Schwefel-induzierte Re- sistenz (SIR) - Schwefeldüngung als nachhaltige Strategie zur Gesunderhaltung von Pflanzen. J. Consum. Protect. Food Safety 2:7-12.

Bloem, E., Haneklaus, S., Salac, I., Wickenhäuser, P., and Schnug, E. 2007b. Facts and fiction about sulfur metabolism in relation to plantpathogen interactions. Plant Biol. 9:596-607.

Bortz, J., Lienert, G. A., and Bohenke, K. 2000. Verteilungsfreie Methoden in der Biostatistik. Springer, Berlin, Heidelberg, New York, Tokyo.

Chivasa, S., Murphy, A. M., Naylor, M., and Carr, J. P. 1997. Salicylic acid interferes with Tobacco mosaic virus replication via a novel salicylhydroxamic acid-sensitive mechanism. Plant Cell 9:547-557.

Dahl, C., Hell, R., Leustek, T., and Knaff, D. 2008. Introduction to sulfur metabolism in phototrophic organisms. Pages 1-14 in: Advances in photosynthesis and respiration (Govindjee, series editor), Sulfur metabolism in phototrophic organisms. Vol. 27. R. Hell, C. Dahl, D. Knaff, and T. Leustek, eds. Springer, Dordrecht, The Netherlands.

De Gara, L., de Pinto, M. C., and Tommasi, F. 2003. The antioxidant system vis-á-vis reactive oxygen species during plant-pathogen interaction. Plant Physiol. Biochem. 41:863-870.

De Kok, L. J., De Kan, J. L., Tànczos, O. G., and Kuiper, P. J. C. 1981. Sulphate induced accumulation of glutathione and frost tolerance of spinach leaf tissue. Physiol. Plant. 53:435-438.

Dubuis, P. H., Marazzi, C., Städler, E., and Mauch, F. 2005. Sulphur deficiency causes a reduction in antimicrobial potential and leads to increased disease susceptibility of oilseed rape. J. Phytopathol. 153:2736.

Foyer, C. H., and Noctor, G. 2009. Redox regulation and photosynthetic organisms: Signaling, acclimation, and practical implications. Antiox. Redox Sign. 11:861-905.

Foyer, C. H., and Rennenberg, H. 2000. Regulation of glutathione synthesis and its role in abiotic and biotic stress defence. Pages 127-153 in: Sulfur Nutrition and Sulfur Assimilation in Higher Plants. C. Brunold, H. Rennenberg, L. J. De Kok, I., Stulen, J. C. Davidian, eds. Paul Haupt Publishers, Bern, Germany.

Gullner, G., and Kömives, T. 2001. The role of glutathione and glutathionerelated enzymes in plant-pathogen interaction. Pages 207-239 in: Significance of Glutathione to Plant Adaptation to the Environment, D. Grill, M. Tausz, and L. J. De Kok, eds. Dordrecht, Boston, Kluwer Academic Publishers, London.

Gullner, G., Tóbiás, I., Fodor, J., and Kömives, T. 1999. Elevation of glutathione level and activation of glutathione-related enzymes affect virus infection in tobacco. Free Radical Res. 31:155-161.

Harms, K., von Ballmoos, P., Brunold, C., Hofgen, R., and Hesse, H 2000. Expression of a bacterial serine acetyltransferase in transgenic potato plants leads to increased levels of cysteine and glutathione. Plant J. 22:335-343.

Haneklaus, S., Bloem, E., and Schnug, E., 2009. Plant disease control by nutrient management: Sulphur. Pages 221-234 in: Disease control in crops: Biological and environmentally friendly approaches. D. Walters, ed. Wiley-Blackwell, Oxford.

Hell, R., and Wirtz, M. 2008. Metabolism of cysteine in plants and phototrophic bacteria. Pages 59-91 in: Advances in photosynthesis and respiration (Govindjee, series editor), Sulfur metabolism in phototrophic organisms. Vol. 27, R. Hell, C. Dahl, D. Knaff, and T. Leustek, eds. Springer, Dordrecht.

Hell, R., Kruse, C., Jost, R., and Lipschis, M. 2005. Molecular analysis of sulfur-based defense reactions in plant-pathogen interactions. Pages 209-216 in: Sulfur Transport and Assimilation in Plants in the Post Genomic Era. K. Saito, L. J. De Kok, I. Stulen, M. Hawkesford, E Schnug, A. Sirko, and H. Rennenberg, eds. Backhuys Publishers, Leiden.

Kataoka, T., Watanabe-Takahashi, A., Hayashi, N., Ohnishi, M., Mimura, T., Buchner, P., Hawkesford, M. J., Yamaya, T., and Takahashi, H. 2004 Vacuolar sulfate transporters are essential determinants controlling internal distribution of sulfate in Arabidopsis. Plant Cell 16:2693-2704.

Kirsten, W. J., and Nordenmark, B. S. 1987. Rapid, automatic, high-precision method for micro, ultramicro, and trace determinations of sulfur. Anal. Chim. Acta 196:59-68.

Klikocka, H., Haneklaus, S., Bloem, E., and Schnug, E. 2005. Influence of sulfur fertilization on infection of potato tubers with Rhizoctonia solani and Streptomyces scabies. J. Plant Nutr. 28:819-833.

Kopriva, S. 2006. Regulation of sulfate assimilation in Arabidopsis and beyond. Ann. Bot-London 97:479-495.

Kopriva, S., and Koprivova, A. 2005. Sulfate assimilation and glutathione synthesis in C4 plants. Photosynth. Res. 86:363-373.

Kopriva, S., and Rennenberg, H. 2004. Control of sulphate assimilation and glutathione synthesis: Interaction with $\mathrm{N}$ and $\mathrm{C}$ metabolism. J. Exp. Bot. 55:1831-1842.

Kopriva, S., Wiedemann, G., and Reski, R. 2007. Sulfate assimilation in basal land plants. What does genomic sequencing tell us? Plant Biol. 9:556-564. 
Kopriva, S., Mugford, S. G., Matthewman, C., and Koprivova, A. 2009. Plant sulfate assimilation genes: Redundancy versus specialization. Plant Cell Rep. 28:1769-1780.

Kruse, C., Jost, R., Lipschis, M., Kopp, B., Hartmann, M., and Hell, R. 2007. Sulfur-enhanced defence: Effects of sulfur metabolism, nitrogen supply, and pathogen lifestyle. Plant Biol. 9:608-619.

Leustek, T. 2002. Sulfate metabolism. In: The Arabidopsis Book. C. R. Somerville and E. M. Meyerowitz, eds. American Society of Plant Biologists, Rockville, MD, U.S.A. doi/10.1199/tab.0017. Published online.

Leustek, T, Martin, M. N., Bick, J. A., and Davies, J. P. 2000. Pathways and regulation of sulfur metabolism revealed through molecular studies. Ann. Rev. Plant Physiol. Plant Mol. Biol. 51:141-166.

Livak, K. J., and Schmittgen, T. D. 2001. Analysis of relative gene expression data using real-time quantitative PCR and the $2^{-\Delta \Delta C T}$ method. Methods 25:402-408.

Ma, Y., Zhou, T., Hong, Y., Fan, Z., and Li, H. 2008. Decreased level of ferrerdoxin 1 in Tobacco mosaic virus-infected tobacco is associated with development of the mosaic symptom. Physiol. Mol. Plant Pathol. 72:39-45.

Müller, M., Zechmann, B., and Zellnig, G. 2004. Ultrastructural localization of glutathione in Cucurbita pepo plants. Protoplasma 223:213-219.

Nikiforova, V. J., Bielecka, M., Gakiere, B., Krueger, S., Rinder, J., Kempa, S., Morcuende, R., Scheible, W. R., Hesse, H., and Hoefgen, R. 2006. Effect of sulfur availability on the integrity of amino acid biosynthesis in plants. Amino Acids 30:173-183.

Nimbalkar, S. B., Harsulkar, A. M., Giri, A. P., Sainani, M. N., Franceschi, V., and Gupta, V. S. 2006. Differentially expressed gene transcripts in roots of resistant and susceptible chickpea plant (Cicer arietinum L.) upon Fusarium oxysporum infection. Physiol. Mol. Plant Pathol. 68:176-188.

Noctor, G., and Foyer, C. H. 1998. Ascorbate and glutathione: Keeping active oxygen under control. Ann. Rev. Plant Physiol. Plant Mol. Biol. 49:229-279.

Noctor, G., Gomez, L., Vanacker, H., and Foyer, C. H. 2002. Interactions between biosynthesis, compartmentation and transport in the control of glutathione homeostasis and signalling. J. Exp. Bot. 53:1283-1304.

Parmar, S., Buchner, P., and Hawkesford, M. J. 2007. Leaf developmental stage affects sulfate depletion and specific sulfate transporter expression during sulfur deprivation in Brassica napus L. Plant Biol. 9:647-653.

Pilch, B., and Grill, D. 1995. Determination of organic and inorganic sulphur by ion chromatography in small quantities of plant material. J. Plant Physiol. 146:10-14.

Rausch, T., Gromes, R., Liedschulte, V., Müller, I., Bogs, J., Galovic, V., and Wachter, A. 2007. Novel insight into the regulation of GSH biosynthesis in higher plants. Plant Biol. 9:565-572.

Rennenberg, H., Polle, A., Martini, N., and Thoene, B. 1988. Interaction of sulphate and glutathione transport in cultured tobacco cells. Planta 176:68-74.

Sajnani, C., Zurita, J. L., Roncel, M., Ortega, J. M., Baron, M., and Ducruet, J. M. 2007. Changes in photosynthetic metabolism induced by tobamovirus infection in Nicotiana benthamiana studied in vivo by thermoluminescence. New Phytol. 175:120-130.

Schnug, E., and Haneklaus, S. 2005. Sulphur deficiency symptoms in oilseed rape (Brassica napus L.) - The aesthetics of starvation. Phyton (Horn, Austria) 45:79-95.

Schnug, E., Haneklaus, S., Borchers, A., and Polle, A. 1995. Relations between sulphur supply and glutathione, ascorbate and glucosinolate con- centrations in Brassica napus varieties. J. Plant Nutr. Soil Sci. 158:67-70.

Sugiyama, A., Nishimura, J., Mochizuki, Y., Inagaki, K., and Sekiya, J. 2004. Homoglutathione synthesis in transgenic tobacco plants expressing soybean homoglutathione synthetase. Plant Biotechnol. 21:79-83.

Tausz, M., Šircelj, H., and Grill, D. 2004. The glutathione system as a stress marker in plant ecophysiology: Is a stress-response concept valid? J. Exp. Bot. 55:1955-1962.

Urbanek-Krajnc, A., Zechmann, B., Zellnig, G., Wonisch, A., and Müller, M. 2007. Elevated thiol levels affect virus infection in Cucurbita pepo plants regenerated via somatic embryogenesis. Acta Phytopathol. Entomol. Hungary 42:253-271.

Wachter, A., Wolf, S., Steininger, H., Bogs, J., and Rausch, T. 2005. Differential targeting of GSH1 and GSH2 is achieved by multiple transcription initiation: Implications for the compartmentation of glutathione biosynthesis in the Brassicaceae. Plant J. 41:15-30.

Xiang, C., and Oliver, D. J. 1998. Glutathione metabolic genes coordinately respond to heavy metals and jasmonic acid in Arabidopsis. Plant Cell 10:1539-1550.

Yang, C., Guo, R., Jie, F., Nettleton, D., Peng, J., Carr, T., Yeakley, J. M., Fan, J. B., and Whitham, S. 2007. Spatial analysis of Arabidopsis thaliana gene expression in response to Turnip mosaic virus infection. Mol. Plant-Microbe Interact. 20:358-370.

Zechmann, B., and Müller, M. 2008. Effects of zucchini yellow mosaic virus infection on the subcellular distribution of glutathione and its precursors in a highly tolerant Cucurbita pepo cultivar. Botany 86:10921100 .

Zechmann, B., and Müller, M. 2010. Subcellular compartmentation of glutathione in dicotyledonous plants. Protoplasma. DOI 10.1007/s00709010-0111-2.

Zechmann, B., Müller, M., and Zellnig, G. 2006a. Intracellular adaptations of glutathione content in Cucurbita pepo L. induced by treatment with reduced glutathione and buthionine sulfoximine. Protoplasma 227:197209.

Zechmann, B., Zellnig, G., and Müller, M. 2006b. Immunocytochemical localization of glutathione precursors in plant cells. J. Electron Microsc. 55:173-181.

Zechmann, B., Zellnig, G., Urbanek-Krajnc, A., and Müller, M. 2007. Artificial elevation of glutathione affects symptom development in ZYMV-infected Cucurbita pepo L. plants. Arch. Virol. 152:747-762.

Zechmann, B., Müller, M., and Zellnig, G. 2008a. Modified levels of cysteine affect glutathione metabolism in plant cells. Pages 193-206 in: Sulfur Assimilation and Abiotic Stress in Plants. N. A. Khan, S. Singh, S. Umar, eds, Springer Verlag, Berlin.

Zechmann, B., Mauch, F., Sticher, L., and Müller, M. 2008b. Subcellular immunocytochemical analysis detects the highest concentrations of glutathione in mitochondria and not in plastids. J. Exp. Bot. 59:4017-4027.

Zhao, F. J., Tausz, M., and De Kok, L. J. 2008. Role of sulfur for plant production in agricultural and natural ecosystems. Pages 417-435 in: Advances in Photosynthesis and Respiration (Govindjee, series editor), Sulfur Metabolism in Phototrophic Organisms, Vol. 27. R. Hell, C. Dahl, D. Knaff, T. Leustek, eds.: Springer, Dordrecht, The Netherlands.

\section{AUTHOR-RECOMMENDED INTERNET RESOURCES}

British BioCell International: www.british-biocell.co.uk German Resource Centre for Biological Material: www.dsmz.de 